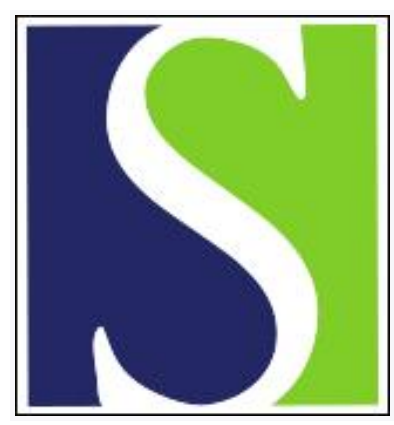

Scand J Work Environ Health 1992;18(2):105-112

https://doi.org/10.5271/sjweh.1604

Issue date: 01 Apr 1992

Magnitude of misclassification bias when using a job-exposure matrix.

by Kauppinen TP, Mutanen PO, Seitsamo JT

Affiliation: Institute of Occupational Health, Helsinki, Finland.

The following articles refer to this text: 2013;39(6):599-608;

2017;43(5):415-425

This article in PubMed: www.ncbi.nlm.nih.gov/pubmed/1604270

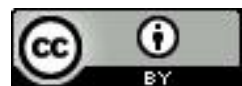




\title{
Magnitude of misclassification bias when using a job-exposure matrix
}

\author{
by Timo P Kauppinen, PhD, Pertti O Mutanen, MSc, Jorma T Seitsamo, MSocSc ${ }^{1}$
}

\begin{abstract}
KAUPPINEN TP, MUTANEN PO, SEITSAMO JT. Magnitude of misclassification bias when using a job-exposure matrix. Scand J Work Environ Health 1992;18:105-12. A job-exposure matrix constructed in Southampton, the United Kingdom, was assessed with the use of 1205 occupational histories collected for a case-referent study on primary liver cancer in Finland. The odds ratios calculated on the basis of the matrix and an assessment by occupational hygienists were compared. The ability of the matrix to detect excess risk was generally satisfactory for chemical and physical agents to which about $10 \%$ or more of the studied population was exposed. If only probable exposure at a high level was assigned to the category of the exposed, an excess risk was usually detectable also when the prevalence of exposure was below $10 \%$. This assessment indicates that the British job-exposure matrix is an acceptably valid screening tool also outside the United Kingdom, provided that the misclassification characteristics of the matrix and the significant differences in exposure between the countries are taken into account.
\end{abstract}

Key terms: prevalence of exposure, sensitivity, specificity.

The job-exposure matrix provides a rapid means with which to convert coded occupational titles into potential exposures in epidemiologic studies. Especially in large population-based studies, it is an easy and systematic method with which to penetrate from proxy variables of exposure, such as industry or occupation, directly to agents and other risk factors. In addition, a job-exposure matrix does not distinguish between diseased and nondiseased subjects, and thus the differential information bias is diminished that could occur if exposure were assessed with the traditional person-byperson approach. However, there are several methodological problems in the use of job-exposure matrices (1). These matrices do not usually take into account the variability of exposure within occupational classes between different workplaces, countries, or calendar periods and therefore may result in false positive and negative exposure assignments for a considerable proportion of the subjects. This misclassification of exposure, even though nondifferential as to the disease status of the subjects, tends to mute the observed risk estimates towards unity. The inaccuracy of the jobexposure matrix approach is diminished if the time and even the factory dimensions are incorporated into the matrices, but an increase in accuracy is often followed by a decrease in general applicability. Therefore, the question of the reliability of the results is always warranted when job-exposure matrices are used to analyze exposure, especially if the matrix used is a simple cross-tabulation of occupational titles and agents.

1 Institute of Occupational Health, Helsinki, Finland.

Reprint requests to: Dr T Kauppinen, Institute of Occupational Health, Topeliuksenkatu 41 a A, SF-00250 Helsinki, Finland.
The validity of job-exposure matrices has been evaluated mainly in comparisons of results provided by the matrix with those of some other method of exposure assessment $(2-5)$. The results given by two different matrices have also been compared (6). Still another approach is to calculate the effect of misclassification on the basis of estimates given to the factors which determine the magnitude of the misclassification bias. The advantage of this method, which is used in the present study, is that it does not require an excess risk for testing because the true risk can be set by assumption. All agents in the matrix can therefore be assessed for misclassification bias.

In this paper we report the magnitude of the misclassification effect on risk estimates when using a British job-exposure matrix in connection with a population-based case-referent study on primary liver cancer in Finland $(7,8)$. We also attempted to elucidate some general principles of the feasibility of the jobexposure matrix approach and the validity of the results in retrospective studies on chronic health hazards.

\section{Material and methods}

The material for testing the job-exposure matrix consisted of chronological occupational histories of 344 cases (primary liver cancer) and 861 referents (stomach cancer or coronary infarction) collected with postal questionnaires from next-of-kin. The mean age of this population was 68.0 years. The schedule of exposure assessment of the study is presented in figure 1 , and it has been described in more detail elsewhere (8). The occupational histories were coded according to the British industrial and occupational classifications to allow for the use of a job-exposure matrix constructed 


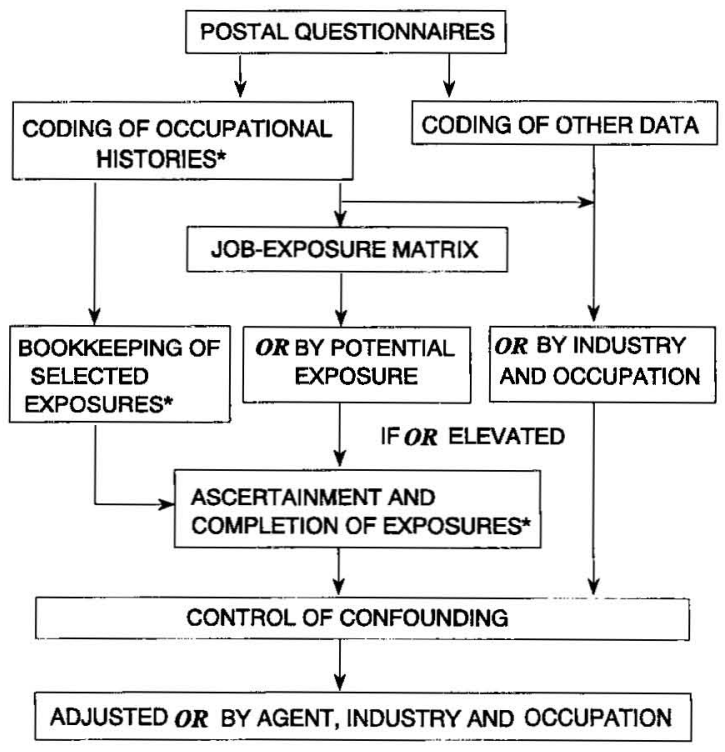

Figure 1. Exposure assessment procedure of the national population-based case-referent study on primary liver cancer in Finland. Operations marked with a star were carried out by occupational hygienists. (JEM = job-exposure matrix, OR = odds ratio)

in the Medical Research Council's Environmental Epidemiology Unit in Southampton, the United Kingdom (5). The British job-exposure matrix is based on combinations of industrial and occupational classes that have been cross-tabulated with 50 chemical agents or other exposure factors. A crude classification of the calendar period (before 1950, after 1950), probability of exposure (low $=1$, high $=2$ ), and level of exposure (low $=1$, high $=2$ ) are also incorporated into the matrix. A computer program was constructed to convert the occupational histories of the subjects into exposure indices for 50 factors. For example, the assignment to class 1122 for agent $\mathrm{X}$ would mean that the person is considered to have had a low probability and level of exposure before 1950 , but a high probability and level of exposure after 1950.

The inclusion of probability and level of exposure in the matrix enables the persons to be rated into semiquantitative classes according to the potential of exposure. One extreme way to use this matrix would be to consider only those exposed persons who have a high probability and level of exposure (exposure = "high" potential exposure in the job-exposure matrix). The other extreme is to consider everyone exposed whose probability of exposure is nonzero according to the matrix (exposure = sum of "low" and "high" potential exposure = "total" potential exposure). The first approach is strict as to the exposure assignment because it accepts only relatively certain exposure, and thus it maximizes the specificity of the exposure assessment at the cost of sensitivity. The second approach is liberal in accepting all potentially exposed persons and thus maximizes sensitivity at the cost of specificity. In this paper we consider both of these approaches.

The method to assess the British job-exposure matrix was based on the theory of misclassification and its effect on the risk estimates. (See, eg, references $9-12$.) It may be proved that the observed odds ratio $\left(\mathrm{OR}^{*}\right)$ depends on the true odds ratio $(\mathrm{OR})$, the prevalence of exposure, the sensitivity of exposure assessment, and the specificity of exposure assessment according to the following formula (modified from reference 10):

$\mathrm{OR}^{*}=\frac{[(\mathrm{Se})(\mathrm{OR})(\mathrm{Pr})+(1-\mathrm{Sp})(1-\mathrm{Pr})][(1-\mathrm{Se})(\mathrm{Pr})+(\mathrm{Sp})(1-\mathrm{Pr})]}{[(\mathrm{Se})(\mathrm{Pr})+(1-\mathrm{Sp})(1-\mathrm{Pr})][(1-\mathrm{Se})(\mathrm{OR})(\mathrm{Pr})+(\mathrm{Sp})(1-\mathrm{Pr})]}$,

where $\mathrm{OR}^{*}=$ the observed (biased) odds ratio, $\mathrm{OR}=$ the true (unbiased) odds ratio, $\operatorname{Pr}=$ the prevalence of exposure (ie, probability of exposure in the reference group during the follow-up period), $\mathrm{Se}=$ sensitivity of exposure assessment (ie, probability that a truly exposed person will be classified as exposed), $\mathrm{Sp}=$ specificity of exposure assessment (ie, probability that a truly unexposed person will be classified as unexposed).

We decided to fix the $O R$ at two values, $O R=5$ and $\mathrm{OR}=2$, representing situations in which the risk is high and moderate, respectively. The prevalence of the studied population's exposure to the 50 agents was estimated on the basis of the exposure indices provided by the job-exposure matrix in the following manner. For example, if the job-exposure matrix gave "high" potential exposure $(\mathrm{H})$ for $10 \%$ and "low" potential exposure (L) for $50 \%$ of the persons under study, the fractions of truly exposed persons $\left(f_{H}\right.$ and $f_{L}$, say, 90 and $10 \%$, respectively) in these classes ( $\mathrm{H}$ and $\mathrm{L}$ ) were estimated by one or several industrial hygienists. The estimation was based on the survey of the occupational titles and work periods of the potentially exposed persons and on various documents concerning the occurrence and level of exposure in Finland. The value of $\mathrm{f}_{\mathrm{H}}$ varied rather widely by agent and ranged from 30 to $100 \%$ (mean $86 \%$, most frequent value $90 \%$ ). The corresponding variation of $f_{L}$ was $0-90 \%$ (mean $18 \%$, most frequent value $10 \%$ ). Because occupational histories are often incompletely reported, a small proportion of exposures usually remains unrecognized by the job-exposure matrix. We assumed for each agent that $10 \%$ of the truly exposed persons would be incorrectly assigned to the class of the unexposed ("total" sensitivity of the job-exposure matrix $=90 \%$ ) and should therefore be added to the exposed group to achieve the best estimate of the prevalence of exposure. The formula to calculate prevalence thus became $\operatorname{Pr}=1.11\left(\mathrm{f}_{\mathrm{H}} \mathrm{H}+\mathrm{f}_{\mathrm{L}} \mathrm{L}\right)$, where the multiplier 1.11 $(=1 / 0.9)$ was due to the incompleteness of the occupational histories. The estimate of the prevalence of exposure in our example would thus be $\operatorname{Pr}=1.11[(0.9)$ $(0.1)+(0.1)(0.5)]=0.16$ (or $16 \%)$. 
For 14 agents it was also possible to check the value of the estimated prevalence against the value of the ascertained exposure in the study population as assessed by a team of occupational hygienists. The agents checked were aromatic amines, asbestos, beryllium, cadmium, chlorophenols, chromium, detergents, dyestuffs, electromagnetic fields, ethylene oxide, lead, organic solvents, other inorganic dusts, and welding fumes. The two estimates of prevalence were usually in good agreement, and, if there was a discrepancy, the estimated prevalence was corrected to correspond with the assessment of the team.

The values of sensitivity and specificity can be directly calculated with the use of their definitions and the estimated values of the truly exposed $(\mathrm{Pr})$ and unexposed $(1-\mathrm{Pr})$ persons. Sensitivity is the proportion of correctly classified exposed persons of all the exposed persons. Specificity is the same proportion for the unexposed persons. In the situation in which only high potential exposure is considered as exposure (subscript $\mathrm{H}$ referring to high potential exposure), $\mathrm{Se}_{\mathrm{H}}=$ $\mathrm{f}_{\mathrm{H}} \mathrm{H} / \mathrm{Pr}$ and $\mathrm{Sp}_{\mathrm{H}}=\left[1-(\mathrm{Pr})-\left(1-\mathrm{f}_{\mathrm{H}}\right) \mathrm{H}\right] /(1-\mathrm{Pr})$. When exposure encompasses all potential exposure assigned by the job-exposure matrix (subscript $\mathrm{T}$ referring to total potential exposure), $\mathrm{Se}_{\mathrm{T}}=0.9$ ( $=90 \%$ by assumption due to incompleteness of the occupational histories) and $\mathrm{Sp}_{\mathrm{T}}=\left[1-(\mathrm{Pr})-\left(1-\mathrm{f}_{\mathrm{H}}\right) \mathrm{H}-\left(1-\mathrm{f}_{\mathrm{L}}\right) \mathrm{L}\right] /$ $(1-\mathrm{Pr})$. Because the values of prevalence, sensitivity, and specificity are often different for men and women, they were calculated separately for both genders.

With the values of $\mathrm{OR}, \mathrm{Pr}, \mathrm{Se}_{\mathrm{H}}$ and $\mathrm{Sp}_{\mathrm{H}}\left(\right.$ or $\mathrm{Se}_{\mathrm{T}}$, and $\mathrm{Sp}_{\mathrm{r}}$ ) it is possible to assess how much the $\mathrm{OR}^{*}$ is biased towards unity due to nondifferential misclassification of exposure. The bias is independent of the size of the study. We also wanted to study the effect of misclassification on the statistical significance of the result. The statistical significance (confidence interval) depends on the size of the study, and therefore we assumed a study of 250 cases and 500 referents (all men or alternatively all women). The lower confidence limits for OR and $\mathrm{OR}^{*}$ were calculated according to the test-based principle (13) except for values taken directly from the original study (in table 3 in the Results section) for which Cornfield's method was used (14).

\section{Results}

The estimated values of the prevalence of exposure and the sensitivity and specificity of the job-exposure matrix are presented in table 1 for the men and women separately. Physical factors such as physical stress, outdoor occupation, and cold were common in the studied population. Surrogates of biological agents, such as contact with animals or the public, were also relatively common for both genders. The most frequently occurring chemical agents were "other", organic dusts (eg, hay dust, flour dust, fodder dust), grain dust, diesel fuel or exhaust (eg, from tractors) and nitrates (eg, from fertilizers), reflecting the high proportion of persons who had at some time during their occupational history been farmers or farmers' wives. Most of the industrial agents were rarer, their prevalence being typically $<5 \%$ and often even $<1 \%$. The women were exposed significantly less frequently than the men. The average prevalence was 9.0 (median 2.3 ) $\%$ for the men and 7.1 (median 0.8 ) $\%$ for the women. The respective values for chemical agents were 6.2 (median 1.4)\% for the men and 4.1 (median 0.7) $\%$ for the women. However, some agents such as detergents, textile dust, and contact with the public or with animals were more common among the women than among the men. No men were assigned to the high potential exposure category for 18 out of 50 agents, and no women for 25 out of 50 agents. In most cases these were agents that were rare $(\operatorname{Pr}<1 \%)$.

The sensitivity and specificity of the job-exposure matrix depended on the agent and varied widely. When only high potential exposure was taken into account, sensitivity was, on the average, low ( $43 \%$ for the men and $45 \%$ for the women) and specificity was high ( $99 \%$ for the men and $98 \%$ for the women). The use of total potential exposure as exposure resulted in higher sensitivity ( $90 \%$ by assumption concerning the incompleteness of the occupational histories) and lower specificity ( $83 \%$ for the men and $87 \%$ for the women).

The effect of misclassification on the $O R^{*}$ is presented in table 2. When the "high" approach was used, the OR* dropped by an average of $30-35 \%$ (from 2 to 1.7 and from 5 to 3.6). The effect was approximately the same for both the men and the women. The drop was much greater for the "total" approach, on the average $80 \%$ (from 2 to 1.2 and from 5 to 1.8 ).

The magnitude of misclassification bias as a function of prevalence for the high and total approaches is illustrated in figures 2 and 3 . With the total approach $\mathrm{OR}^{*}$ decreased and the misclassification bias increased when the agent became rarer. With the high approach OR* decreased when the agent became more common. When the prevalence was below $10 \%$, the misclassification bias was relatively small, and the restricting factor was not misclassification, but rather the lack of heavily exposed cases when the agent was rare.

Solvents and welding fumes gave statistically significantly elevated values in the original study and thus allowed a direct comparison between the job-exposure matrix method and the assessment of a team of occupational hygienists. The results of this comparison are presented in table 3 . The observed pattern for the OR* was similar for both methods, but the occupational hygienic analysis provided somewhat higher OR* values than the analysis with the job-exposure matrix.

\section{Discussion}

The British job-exposure matrix used in a Finnish casereferent study on liver cancer turned out to be rela- 
Table 1. Estimated prevalences of exposure and the sensitivities and specificities of the British job-exposure matrix (JEM) for the men and women in the Finnish case-referent study on primary liver cancer. ( $\mathrm{Pr}=$ prevalence of exposure in the reference group, $\mathrm{Se}_{\mathrm{H}}=$ sensitivity of the JEM when only "high" potential exposure was considered as exposure, $\mathrm{Sp}_{\mathrm{H}}=\mathrm{specificity}_{\mathrm{f}}$ of the JEM when only "high" potential exposure was considered as exposure, $\mathrm{Se}_{\mathrm{T}}=$ sensitivity of the JEM when all ("total") potential exposure was considered as exposure, $\mathrm{Sp}_{\mathrm{T}}=$ specificity of the JEM when all ("total") potential exposure was considered as exposure, NA = "high" potential exposure approach not applicable because nobody was classified as exposed by the JEM)

\begin{tabular}{|c|c|c|c|c|c|c|c|c|c|c|}
\hline \multirow[b]{2}{*}{ Agent } & \multicolumn{5}{|c|}{ Men } & \multicolumn{5}{|c|}{ Women } \\
\hline & $\underset{(\%)}{\operatorname{Pr}}$ & $\begin{array}{l}\mathrm{Se}_{H} \\
(\%)\end{array}$ & $\begin{array}{l}\mathrm{Sp}_{H} \\
(\%)\end{array}$ & $\begin{array}{l}\mathrm{Se}_{\mathrm{T}} \\
(\%)\end{array}$ & $\begin{array}{l}\mathrm{Sp}_{\mathrm{T}} \\
(\%)\end{array}$ & $\begin{array}{c}\mathrm{Pr} \\
(\%)\end{array}$ & $\begin{array}{l}\mathrm{Se}_{H} \\
(\%)\end{array}$ & $\begin{array}{l}S p_{H} \\
(\%)\end{array}$ & $\begin{array}{l}\mathrm{Se}_{\mathrm{T}} \\
(\%)\end{array}$ & $\begin{array}{l}\mathrm{Sp}_{\mathrm{T}} \\
(\%)\end{array}$ \\
\hline Physical stress & 56 & 77 & 89 & 90 & 51 & 54 & 71 & 91 & 90 & 37 \\
\hline Outdoor occupation & 50 & 88 & 90 & 90 & 69 & 44 & 89 & 92 & 90 & 88 \\
\hline Other organic dusts & 41 & 2 & 100 & 90 & 93 & 48 & 2 & 100 & 90 & 91 \\
\hline Grain dust & 37 & 4 & 100 & 90 & 94 & 45 & 4 & 100 & 90 & 92 \\
\hline Contact with animals & 36 & 89 & 94 & 90 & 90 & 46 & 84 & 92 & 90 & 46 \\
\hline Cold & 30 & 4 & 100 & 90 & 62 & 16 & 2 & 100 & 90 & 62 \\
\hline Diesel fuel and fumes & 28 & 28 & 99 & 90 & 43 & 2.6 & 7 & 100 & 90 & 58 \\
\hline Nitrates, nitrites & 20 & NA & NA & 90 & 77 & 4.8 & NA & NA & 90 & 60 \\
\hline Wood dust & 18 & 83 & 98 & 90 & 84 & 4.9 & 87 & 100 & 90 & 98 \\
\hline Other inorganic dusts & 13 & 19 & 100 & 90 & 89 & 2.9 & 22 & 100 & 90 & 98 \\
\hline Contact with the public & 11 & 61 & 99 & 90 & 90 & 21 & 72 & 98 & 90 & 87 \\
\hline Asbestos & 11 & NA & NA & 90 & 75 & 1.6 & NÄ & NA & 90 & 97 \\
\hline Synthetic adhesives & 11 & 61 & 97 & 90 & 66 & 2.5 & 20 & 100 & 90 & 83 \\
\hline Natural adhesives & 9.3 & 65 & 97 & 90 & 74 & 2.1 & 7 & 100 & 90 & 84 \\
\hline Soot, tar, mineral oils & 8.6 & 48 & 99 & 90 & 64 & 1.8 & 26 & 100 & 90 & 90 \\
\hline Organic solvents & 7.4 & 41 & 100 & 90 & 84 & 3.0 & 46 & 100 & 90 & 94 \\
\hline Heat & 6.7 & 26 & 100 & 90 & 95 & 4.3 & NA & NA & 90 & 64 \\
\hline Paints and pigments & 5.2 & 48 & 100 & 90 & 79 & 0.9 & 66 & 100 & 90 & 98 \\
\hline Welding fumes & 3.6 & 44 & 100 & 90 & 93 & 0.1 & NA & NA & 90 & 100 \\
\hline Antiknock agents & 3.4 & NA & NA & 90 & 97 & 0.3 & NA & NA & 90 & 100 \\
\hline Polycyclic aromatic hydrocarbons & 3.0 & 27 & 100 & 90 & 82 & 0.8 & NA & NA & 90 & 93 \\
\hline Lead and its compounds & 2.6 & 49 & 100 & 90 & 77 & 0.5 & 39 & 100 & 90 & 95 \\
\hline Benzene & 2.5 & 41 & 99 & 90 & 87 & 1.3 & 19 & 100 & 90 & 91 \\
\hline Chromium and chromates & 2.5 & 4 & 100 & 90 & 58 & 0.6 & NA & NA & 90 & 90 \\
\hline Degreasing agents & 2.3 & 31 & 100 & 90 & 87 & 1.5 & 52 & 100 & 90 & 95 \\
\hline Formaldehyde & 2.3 & NA & NA & 90 & 81 & 0.9 & NA & NA & 90 & 93 \\
\hline Electromagnetic fields & 2.2 & 32 & 100 & 90 & 88 & 0.2 & NA & NA & 90 & 99 \\
\hline Waxes and polishes & 1.4 & NA & NA & 90 & 88 & 1.8 & NA & NA & 90 & 85 \\
\hline Cutting fluids & 1.4 & 70 & 100 & 90 & 97 & 0.1 & NA & NA & 90 & 99 \\
\hline Detergents & 1.3 & 21 & 100 & 90 & 92 & 22 & 82 & 84 & 90 & 64 \\
\hline Printing inks & 1.2 & 73 & 100 & 90 & 98 & 0.7 & 79 & 100 & 90 & 92 \\
\hline Chlorophenols & 1.1 & NA & NA & 90 & 49 & 0.5 & NA & NA & 90 & 54 \\
\hline $\begin{array}{l}\text { Dyestuffs } \\
\text { Destus }\end{array}$ & 1.1 & 28 & 100 & 90 & 94 & 0.8 & NA & NA & 90 & 94 \\
\hline Coal dust & 1.1 & 64 & 99 & 90 & 97 & 0.1 & NA & NA & 90 & 99 \\
\hline Textile dust & 1.1 & 43 & 100 & 90 & 95 & 15 & 20 & 100 & 90 & 96 \\
\hline Aromatic amines & 1.0 & 52 & 99 & 90 & 91 & 0.4 & 29 & 100 & 90 & 95 \\
\hline Cadmium and its compounds & 1.0 & 17 & 100 & 90 & 93 & 0.3 & NA & NA & 90 & 97 \\
\hline Styrene & 1.0 & NA & NA & 90 & 92 & 0.3 & NA & NA & 90 & 98 \\
\hline Herbicides & 0.9 & NA & NA & 90 & 58 & 0.2 & 90 & 100 & 90 & 57 \\
\hline Ultraviolet light except sunlight & 0.9 & NA & NA & 90 & 93 & 0.8 & NA & NA & 90 & 93 \\
\hline Soldering fumes & 0.8 & NA & NA & 90 & 94 & 0.1 & NA & NA & 90 & 99 \\
\hline Arsenic and its compounds & 0.6 & NA & NA & 90 & 51 & 0.7 & 25 & 100 & 90 & 53 \\
\hline Mercury and its compounds & 0.5 & NA & NA & 90 & 76 & 0.1 & NA & NA & 90 & 92 \\
\hline Acrylonitrile & 0.2 & NA & NA & 90 & 98 & 0.2 & NA & NA & 90 & 99 \\
\hline Carbon tetrachloride & 0.2 & NA & NA & 90 & 85 & 0.6 & 79 & 100 & 90 & 94 \\
\hline Epoxy resins & 0.2 & 30 & 100 & 90 & 90 & $<0.1$ & NA & NA & 90 & 96 \\
\hline lonizing radiation & 0.2 & NA & NA & 90 & 99 & 0.2 & NA & NA & 90 & 98 \\
\hline Beryllium and its compounds & 0.1 & NA & NA & 90 & 98 & 0.1 & NA & NA & 90 & 99 \\
\hline Polychlorinated biphenyls & 0.1 & NA & NA & 90 & 93 & 0.1 & NA & NA & 90 & 91 \\
\hline Ethylene oxide & $<0.1$ & NA & NA & 90 & 98 & $<0.1$ & NA & NA & 90 & 98 \\
\hline
\end{tabular}

tively powerful in revealing elevated risk. The ability of the matrix to detect the true excess was strongly influenced by the prevalence of exposure and by the way the matrix was used (figures 2 and 3 ). The misclassification bias between the individual agents of the matrix varied widely, from nearly unbiased to very biased. The misclassification characteristics of the individual agents can be identified from table 2 .

The job-exposure matrix indicated the excess risk for agents that were common (prevalence about 10\% or more) fairly well, whereas rare agents (prevalence about $1 \%$ or less) were difficult or impossible to de- tect because of the lack of exposed cases with the high approach or because of strong misclassification bias with the total approach. For the moderately common agents (prevalence $1-10 \%$ ), the high approach indicated an excess (OR* at least 1.5) for most of the agents when the OR was 2 , but the total approach generally failed. When the OR was 5 , both approaches indicated an excess, but the high approach was much less biased (OR* about 4 versus OR* about 2 with the total approach).

When a study is of the size of ours, the values are statistically significant when the prevalence of exposure 
Table 2. Observed (biased) odds ratio from the British job-exposure matrix (JEM) when the true odds ratio (OR) was assumed to equal two or five. Statistical significance at the $5 \%$ level (two-sided test) of the results is calculated for a study population of 250 cases and 500 referents (all men or all women). ${ }^{2}$ (High = only high potential exposure assigned by the JEM considered as exposure, total = all (total) potential exposure assigned by the JEM considered as exposure)

\begin{tabular}{|c|c|c|c|c|c|c|c|c|}
\hline \multirow{3}{*}{ Agent } & \multicolumn{4}{|c|}{ Men } & \multicolumn{4}{|c|}{ Women } \\
\hline & \multicolumn{2}{|c|}{ High } & \multicolumn{2}{|c|}{ Total } & \multicolumn{2}{|c|}{ High } & \multicolumn{2}{|c|}{ Total } \\
\hline & $\mathrm{OR}=2$ & $O R=5$ & $O R=2$ & OR $=5$ & $O R=2$ & $\mathrm{OR}=5$ & $\mathrm{OR}=2$ & $\mathrm{OR}=5$ \\
\hline Physical stress & $1.5^{\star}$ & $2.3^{\star}$ & $1.4^{\star}$ & $2.1^{*}$ & $1.5^{\star}$ & $2.7^{*}$ & $1.3^{+}$ & $1.8^{*}$ \\
\hline Outdoor occupation & $1.7^{*}$ & $3.1^{*}$ & $1.5^{\star}$ & $2.6^{*}$ & $1.7^{\star}$ & $3.5^{*}$ & $1.7^{*}$ & $3.3^{*}$ \\
\hline Other organic dusts & $1.4^{+}$ & $1.8^{+}$ & $1.8^{\star}$ & $3.6^{*}$ & $1.3^{+}$ & $1.6^{+}$ & $1.7^{+}$ & $3.4^{*}$ \\
\hline Grain dust & $1.4^{+}$ & $1.9^{+}$ & $1.8^{*}$ & $3.7^{\star}$ & $1.3^{+}$ & $1.7^{+}$ & $1.8^{\star}$ & $3.5^{\star}$ \\
\hline Contact with animals & $1.8^{*}$ & $3.7^{\star}$ & $1.7^{\star}$ & $3.5^{\star}$ & $1.7^{\star}$ & $3.0^{\star}$ & $1.4^{\star}$ & $2.0^{*}$ \\
\hline Cold & $1.5^{+}$ & $2.1^{*}$ & $1.4^{\star}$ & $2.4^{\star}$ & $1.6^{+}$ & $2.9^{+}$ & $1.3^{+}$ & $2.0^{*}$ \\
\hline Diesel fuel and fumes & $1.6^{\star}$ & $2.4^{\star}$ & $1.3^{+}$ & $1.9^{*}$ & $1.9^{+}$ & $4.2^{+}$ & $1.0^{+}$ & $1.2^{+}$ \\
\hline Nitrates, nitrites & NA & NA & $1.5^{\star}$ & $2.7^{\star}$ & NA & NA & $1.1^{+}$ & $1.4^{\star}$ \\
\hline Wood dust & $1.8^{*}$ & $4.0^{*}$ & $1.5^{\star}$ & $2.9^{\star}$ & $1.9^{\star}$ & $4.5^{\star}$ & $1.7^{\star}$ & $3.7^{\star}$ \\
\hline Other inorganic dusts & $1.7^{+}$ & $3.2^{*}$ & $1.5^{\star}$ & $3.0^{\star}$ & $1.9^{+}$ & $4.2^{*}$ & $1.6^{+}$ & $3.2^{*}$ \\
\hline Contact with the public & $1.8^{\star}$ & $3.9^{\star}$ & $1.5^{*}$ & $3.0^{\star}$ & $1.8^{*}$ & $3.6^{\star}$ & $1.6^{*}$ & $3.2^{\star}$ \\
\hline Asbestos & NA & NA & $1.3^{+}$ & $2.1^{*}$ & NA & NA & 1.3 & $2.2^{*}$ \\
\hline Synthetic adhesives & $1.6^{*}$ & $3.2^{\star}$ & $1.2^{+}$ & $1.8^{\star}$ & $1.7^{+}$ & $3.5^{\star}$ & $1.1^{+}$ & $1.5^{\star}$ \\
\hline Natural adhesives & $1.6^{\star}$ & $3.3^{\star}$ & $1.2^{+}$ & $1.9^{\star}$ & 1.7 & $3.5^{+}$ & 1.1 & $1.4^{*}$ \\
\hline Soot, tar, mineral oils & 1.8 & $3.9^{*}$ & $1.2^{+}$ & $1.7^{\star}$ & 1.9 & $4.4^{\star}$ & 1.1 & $1.5^{*}$ \\
\hline Organic solvents & $1.8^{*}$ & $3.9^{*}$ & $1.3^{+}$ & $2.2^{*}$ & $1.9^{+}$ & $4.3^{*}$ & $1.3^{+}$ & $2.3^{*}$ \\
\hline Heat & $1.8^{+}$ & $3.8^{\star}$ & $1.6^{\star}$ & $3.2^{*}$ & NA & NA & $1.1^{+}$ & $1.4^{\star}$ \\
\hline Paints and pigments & $1.9+$ & $4.5^{\star}$ & $1.2^{+}$ & $1.7^{\star}$ & 2.0 & $4.9^{\star}$ & 1.3 & $2.2^{*}$ \\
\hline Welding fumes & $2.0^{+}$ & $4.6^{\star}$ & $1.3^{+}$ & $2.3^{*}$ & NA & NA & 1.2 & 1.8 \\
\hline Antiknock agents & NA & NA & $1.5^{+}$ & $3.0^{*}$ & NA & NA & 1.5 & $3.0^{+}$ \\
\hline Polycyclic aromatic hydrocarbons & $1.9^{+}$ & $4.2^{*}$ & $1.1^{+}$ & $1.5^{\star}$ & NA & NA & 1.1 & $1.4^{+}$ \\
\hline Lead and its compounds & $1.9^{+}$ & $4.3^{\star}$ & $1.1^{+}$ & $1.4^{*}$ & 1.9 & $4.5^{+}$ & 1.1 & $1.3^{+}$ \\
\hline Benzene & $1.5^{+}$ & $2.9^{\star}$ & $1.2^{+}$ & $1.6^{+}$ & 1.5 & $2.9^{+}$ & 1.1 & $1.5^{+}$ \\
\hline Chromium and chromates & $1.9^{+}$ & $4.2^{+}$ & $1.0^{+}$ & $1.2^{+}$ & NA & NA & 1.0 & $1.2^{+}$ \\
\hline Degreasing agents & $1.9^{+}$ & $4.3^{\star}$ & $1.1^{+}$ & $1.6^{\star}$ & 1.9 & $4.5^{\star}$ & 1.2 & $1.8^{*}$ \\
\hline Formaldehyde & NA & NA & $1.1^{+}$ & $1.4^{*}$ & NA & NA & 1.1 & $1.4^{+}$ \\
\hline Electromagnetic fields & 1.9 & $4.3^{*}$ & 1.1 & $1.6^{\star}$ & NA & NA & 1.1 & 1.4 \\
\hline Waxes and polishes & NA & NA & 1.1 & $1.4^{+}$ & NA & NA & 1.1 & $1.4^{*}$ \\
\hline Cutting fluids & 1.9 & $4.5^{\star}$ & 1.3 & $2.3^{\star}$ & NA & NA & 1.1 & 1.4 \\
\hline Detergents & 1.9 & $4.4^{+}$ & 1.1 & $1.5^{\star}$ & $1.5^{\star}$ & $2.8^{\star}$ & $1.1^{+}$ & $1.4^{*}$ \\
\hline Printing inks & 1.9 & $4.5^{\star}$ & 1.4 & $2.4^{\star}$ & NA & NA & 1.1 & $1.3^{+}$ \\
\hline Chlorophenols & NA & NA & 1.0 & $1.1^{+}$ & NA & NA & 1.0 & $1.0^{+}$ \\
\hline Dyestuffs & 2.0 & $4.9^{*}$ & 1.1 & $1.6^{\star}$ & NA & NA & 1.1 & $1.4^{+}$ \\
\hline Coal dust & 1.5 & $3.0^{\star}$ & 1.2 & $1.9^{\star}$ & NA & NA & 1.1 & 1.4 \\
\hline Textile dust & 1.9 & $4.5^{\star}$ & 1.2 & $1.7^{\star}$ & $1.7^{+}$ & $3.1^{*}$ & $1.8^{\star}$ & $4.0^{*}$ \\
\hline Aromatic amines & 1.3 & $2.2^{+}$ & 1.1 & $1.3^{+}$ & 1.3 & $2.2^{+}$ & 1.1 & $1.3^{+}$ \\
\hline Cadmium and its compounds & 1.9 & $4.4^{+}$ & 1.1 & $1.5^{+}$ & NA & NA & 1.1 & $1.4^{+}$ \\
\hline Styrene & NA & NA & 1.1 & $1.4^{+}$ & NA & NA & 1.1 & $1.4^{+}$ \\
\hline Herbicides & NA & NA & 1.0 & $1.1^{+}$ & 1.9 & 4.6 & 1.0 & 1.0 \\
\hline Ultraviolet light except sunlight & NA & NA & 1.1 & $1.4^{+}$ & NA & NA & 1.1 & $1.4^{+}$ \\
\hline Soldering fumes & NA & NA & 1.1 & $1.4^{+}$ & NA & NA & 1.1 & 1.4 \\
\hline Arsenic and its compounds & NA & NA & 1.0 & $1.0^{+}$ & 1.9 & $4.5^{+}$ & 1.0 & $1.0^{+}$ \\
\hline Mercury and its compounds & NA & NA & 1.0 & $1.1^{+}$ & NA & NA & 1.0 & 1.0 \\
\hline Acrylonitrile & NA & NA & 1.1 & 1.4 & NA & NA & 1.1 & 1.4 \\
\hline Carbon tetrachloride & NA & NA & 1.0 & 1.0 & 1.9 & $4.6^{*}$ & 1.1 & $1.3^{+}$ \\
\hline Epoxy resins & 1.5 & 3.0 & 1.0 & 1.0 & NA & NA & 1.0 & 1.0 \\
\hline lonizing radiation & NA & NA & 1.1 & 1.4 & NA & NA & 1.1 & 1.4 \\
\hline Beryllium and its compounds & NA & NA & 1.0 & 1.2 & NA & NA & 1.0 & 1.2 \\
\hline Polychlorinated biphenyls & NA & NA & 1.0 & 1.0 & NA & NA & 1.0 & 1.0 \\
\hline Ethylene oxide & NA & NA & 1.0 & 1.0 & NA & NA & 1.0 & 1.1 \\
\hline
\end{tabular}

a Notations: * $=$ both true and observed OR statistically significant; ${ }^{+}=$true OR statistically significant, observed OR not; no notations $=$ neither of $\mathrm{OR}$ values statistically significant; $\mathrm{NA}=$ high approach not applicable because nobody was classified as exposed by the JEM.

exceeds about $10 \%$ when $\mathrm{OR}=2$, or about $1 \%$ when $\mathrm{OR}=5$. The difference between the high and total approaches in this respect is small, the total approach reaching statistical significance slightly more frequently. When the study is smaller than the example study, the OR* is not affected, but the confidence interval tends to be wider. Consequently fewer statistically significant results are observed and also the applicability of the high approach may decrease. The situation is the contrary for a study that is larger than the example study.
This assessment of misclassification bias suggests that the British job-exposure matrix is an acceptably valid tool with which to survey risks for certain agents. However, the results should be considered as highly biased if the agent is so rare that no one can be assigned to the category of a high probability and level of exposure with the job-exposure matrix. In the present study, an OR as high as 5 could not be detected by the job-exposure matrix for the following agents: ethylene oxide, polychlorinated biphenyls, beryllium, ionizing radiation, acrylonitrile, mercury, solder 


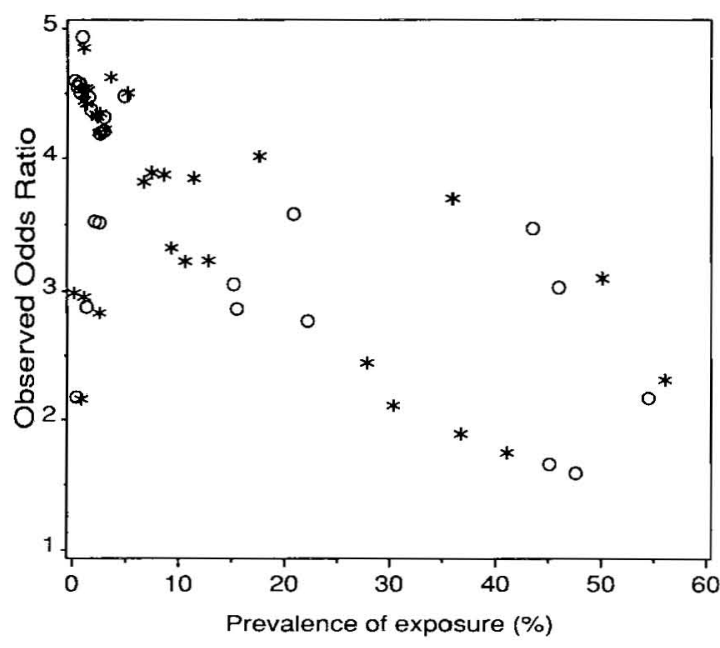

Figure 2. Observed odds ratios by prevalence of exposure when the true odds ratio was assumed to be 5 and only "high" potential exposure assigned by the job-exposure matrix was considered as exposure. (stars $=$ men, circles $=$ women)

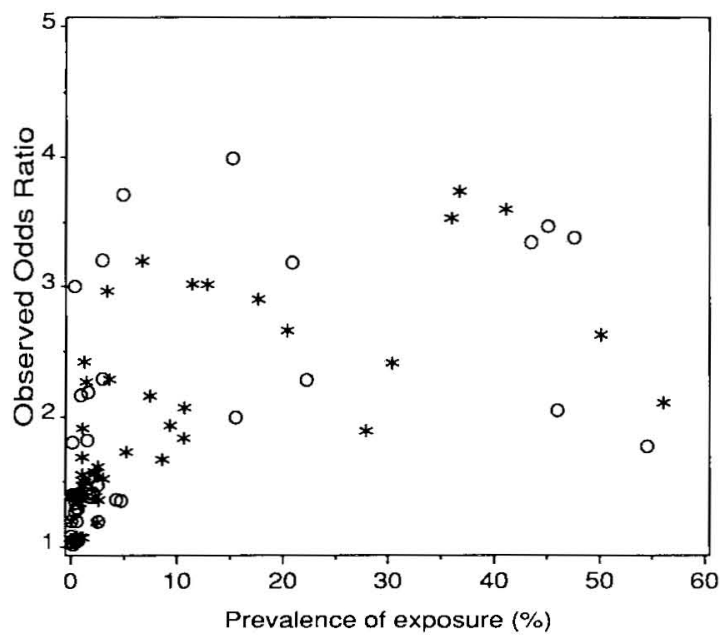

Figure 3. Observed odds ratios by prevalence of exposure when the true odds ratio was assumed to be 5 and all ("total") potential exposure assigned by the job-exposure matrix was considered as exposure. (stars $=$ men, circles $=$ women)

fumes, ultraviolet light, styrene, chlorophenols, waxes/ polishes, and formaldehyde. For these agents, the $\mathrm{OR}^{*}$ was, in all cases, $<1.5$ because of misclassification or incalculable because of a lack of subjects in the category of a high probability and level of exposure. This result cannot be generalized because, in a larger study or in a population with different prevalences of exposure, the agents not working properly in the analysis with the job-exposure matrix would probably have been different from those listed. In addition, because of the population characteristics of the present study,
Table 3. Primary liver cancer and exposure to solvents and welding fumes according to the job-exposure matrix and assessment by a team of occupational hygienists. $(O R=$ odds ratio, $95 \% \mathrm{Cl}=95 \%$ confidence interval, $\mathrm{High}=$ high probability and level of exposure, Total = all potential exposure, Heavy $=$ at least 10 years of a high level of exposure, Any = any time at any level of exposure)

\begin{tabular}{lcl}
\hline Agent and exposure & $\begin{array}{c}\text { Exposed } \\
\text { cases } \\
\text { (N) }\end{array}$ & OR \\
\hline
\end{tabular}

Analysis by the job-exposure matrix

Organic solvents (chlorinated and nonchlorinated)

High

Men

Women

Both

$\begin{array}{lll}5 & 0.8 & 0.3-2.1 \\ 4 & 2.4 & 0.7-9.0\end{array}$

Total

Men

Women

Both

$0.5-2.4$

Degreasing agents (chlorinated

hydrocarbons)

High

\section{Men}

Women

Both

\section{$36 \quad 0.9 \quad 0.6-1.3$}

$\begin{array}{lll}19 & 2.0 & 1.1-3.7\end{array}$

$\begin{array}{lll}55 & 1.0 & 0.7-1.5\end{array}$

Total

Men

Women

Both

$\begin{array}{lll}1 & - & \\ 3 & 3.5 & 0.7-18 \\ 4 & 1.4 & 0.4-4.6 \\ & & \\ 20 & 0.7 & 0.4-1.1 \\ 14 & 1.6 & 0.8-3.1 \\ 34 & 0.9 & 0.6-1.3\end{array}$

Welding fumes

High

$\begin{array}{llll}\text { Men } & 6 & 4.2 & 1.2-14\end{array}$

Total

Men

$18 \quad 1.1 \quad 0.6-1.9$

Assessment by a team of occupational hygienists

Organic solvents (mainly

nonchlorinated hydrocarbons

for the men but chlorinated

hydrocarbons for the women)

Any

Men

Women

$\begin{array}{lll}7 & 0.6 & 0.3-1.3 \\ 7 & 3.4 & 1.3-8.6\end{array}$

Both

$14 \quad 1.0$

$0.6-2.0$

Welding fumes

Heavy

$\begin{array}{llll}\text { Men } & 5 & 13.5 & 2.1-88\end{array}$

Any

Men

$6 \quad 1.4 \quad 0.5-3.5$

the job-exposure matrix was generally less powerful for the women than for the men (lower prevalence of exposure for the women).

The assumption that the occupational histories are $90 \%$ complete as to the exposures $\left(\mathrm{Se}_{\mathrm{T}}=0.9\right)$ may seem arbitrary and debatable because the correct figure is probably not $90 \%$, and it is likely to vary by agent. According to our experience, however, the most relevant exposures (high level, long term) are revealed with high probability in these kinds of studies, and the underreporting concerns mainly short-term jobs and 
exposures which generally contribute less than the longterm exposures to the risk of chronic diseases. Therefore the figure of $90 \%$ may be too high as an estimate of all lifetime exposures, but it is still a reasonable estimate of long-term exposures relevant to the magnitude of the risk. In addition, the misclassification bias is, in most cases, not affected much by $\mathrm{Se}_{\mathrm{T}}$. The relative weight of specificity as compared with sensitivity can be seen in tables 1 and 2 . For example, the $\mathrm{OR}^{*}$ for dyestuffs is almost unbiased (4.9 versus 5) even though $\mathrm{Se}_{\mathrm{H}}$ is only $28 \%$. The OR* of cadmium $\left(\mathrm{Se}_{\mathrm{H}}=0.17 ; \mathrm{Sp}_{\mathrm{H}}=1.00 ; \mathrm{OR}^{*}=4.4\right)$ is much less biased than that of aromatic amines $\left(\mathrm{Se}_{\mathrm{H}}=0.52\right.$; $\mathrm{Sp}_{\mathrm{H}}=0.99 ; \mathrm{OR}^{*}=2.2$ ) even though the specificity for cadmium is only $1 \%$ higher. The assumption concerning the completeness of the occupational histories is thus not likely to change the conclusions of this study.

The preferable way to use the grading of exposure with this job-exposure matrix is the "high" strategy, with which only a high probability and level of exposure is considered to be exposure. This strategy is likely to work well when the prevalence of exposure is approximately $10 \%$ or less, except when there are no heavily exposed cases. However, use of the total approach also provides additional information about the plausibility of the observed risk. If the total and high approaches show an increasing or a flat exposureresponse relationship, the result can be considered to be in keeping with occupational etiology. A decreasing exposure-response relationship indicates that the observed risk is probably caused by chance or bias. The job-exposure matrix can also be used as a preliminary survey tool to trigger a more-detailed assessment of exposure, as done in the Finnish study on liver cancer (see figure 1). In that study, an $\mathrm{OR}^{*}$ of at least 1.5 on the basis of at least five exposed cases and a flat or increasing exposure-response relationship were used as criteria for the reassessment of exposure carried out by occupational hygienists.

The differences in the exposure patterns between the United Kingdom and Finland turned out to be small in most cases. The agreement of the Finnish hygienists with the British job-exposure matrix was good in the category of a high probability and level of exposure. Agreement was worse for some agents, especially in the lower categories of exposure. Examples of such agents are cold, asbestos, chlorophenols, aromatic amines, and arsenic. The poor agreement can be explained in some cases by true differences in exposure, such as the colder climate of Finland (cold). Another reason for the differences is the assessment criteria, that is, the limits between negligible, low, and high probability and those between a low and high level of exposure. It is likely that partially different criteria have been used in the construction of the job-exposure matrix in the United Kingdom as compared with its assessment in Finland. Sometimes it is difficult even to specify the criteria unequivocally because the job- exposure matrix omits relevant factors influencing exposure. For example, it can be argued that the probability of exposure to asbestos in construction work is both high (in the case of long employment) and low (in the case of short employment). The results of this assessment must therefore be considered as no more than approximate estimates derived from a comparison of the job-exposure matrix with a team of occupational hygienists basing the assessment on the available occupational histories, and on the knowledge of the occurrence and level of exposure in their own country.

The economic structure of the country, the time period considered, and the gender and age distributions of the studied population mainly influence the prevalences of exposure. The bias due to misclassification is therefore different in every study and for every jobexposure matrix. The Finnish population used in the present assessment was a retrospective one whose occupational exposures dated mainly from the 1920s to the 1970 s. Over $50 \%$ of the work force was employed in agriculture in the $1920 \mathrm{~s}$, but since then this percentage has dropped to about 8\% (late 1980s). The share of industry has grown slowly from below $20 \%$ to about $25 \%$ during the same period. The current main branches of industry are metals and metal products (37\% of the employees in industry); wood, paper, and publishing $(26 \%)$; food and beverage $(12 \%)$; textile and garment $(11 \%)$; and chemical, rubber, and plastics $(8 \%)$. According to the statistics, the economic structure of Australia, New Zealand, Japan, the United States, Canada, and many countries in northern, western and middle Europe does not differ very much from that of Finland (15). The misclassification effects of the British job-exposure matrix, if applied to retrospective populations in these countries, would probably be close to those reported in this paper. However, if this job-exposure matrix is used outside the United Kingdom, it is worth checking the exposure codes assigned by the job-exposure matrix for those industrial and occupational categories which are common in the studied population. Incorrect assignments due to national differences in these categories may strongly influence the sensitivity, specificity, and prevalence, and thus also the misclassification bias and the observed odds ratios. This kind of checking is not laborious and could improve the validity of the results by decreasing the misclassification of exposure.

In summary, misclassification and the corresponding bias in odds ratios when the British job-exposure matrix was used depended strongly on two factors, (i) the prevalence of exposure and (ii) the inclusion criterion for exposure. The ability of the matrix to detect excess risk was satisfactory for agents with a prevalence of about $10 \%$ or more. If only probable exposure to a high level was considered to be true exposure, the misclassification bias due to the use of the job-exposure matrix was relatively small, and an excess risk was usually detectable also when the prevalence was from 
1 to $10 \%$. In large studies, even rarer agents can be surveyed, provided that there are subjects who are exposed to a high level with a high probability. It is therefore recommended that the true exposure be restricted to exposure of high probability and high level. However, supplementing this approach by a separate analysis including, for example, all or all remaining categories of potential exposure could provide additional information on the plausibility of the observed risk. Applying this job-exposure matrix to a population from another country probably does not bias the results seriously, provided that the assignments of the job-exposure matrix for those industries and occupations that are common in the studied population are checked and corrected when necessary.

\section{Acknowledgments}

We are very grateful to Dr B Pannett and Dr D Coggon, Medical Research Council, Environmental Epidemiology Unit, Southampton, United Kingdom, for kindly providing their job-exposure matrix for our study; to Ms R Riala, Dr M Hietanen, and Mr A Anttila, Institute of Occupational Health, Helsinki, for their valuable contribution to the exposure assessment; and to Ms T Kaustia for her linguistic revision of the manuscript.

\section{References}

1. Coughlin SS, Chiazze L. Job-exposure matrices in epidemiologic research and medical surveillance. In: Rempel D, ed. Medical surveillance in the workplace. Philadelphia: Hanley and Belfus Inc, 1990:633-46. (Occupational medicine, state of the art reviews; vol 5, no 3 ).

2. Hinds MW, Kolonel LN, Lee J. Application of a jobexposure matrix to a case-control study of lung cancer. J Natl Cancer Inst 1985;75:193-7.
3. Hoar SK, Morrison AS, Cole P, Silverman DT. An occupation and exposure linkage system for the study of occupational carcinogenesis. J Occup Med 1980;22: $722-6$.

4. Macaluso M, Vineis $P$, Continenza D, Ferrario F, Pisani $P$, Andisio R. Job exposure matrices - experience in Italy. In: Acheson ED, ed. Job exposure matrices. Southampton: Medical Research Council, Environmental Epidemiology Unit, 1983:22-30.

5. Pannett B, Coggon D, Acheson ED. A job-exposure matrix for use in population based studies in England and Wales. Br J Ind Med 1985;42:777-83.

6. Linet MS, Stewart WF, Van Natta ML, McCaffrey LD, Szklo M. Comparison of methods for determining occupational exposure in a case-control interview study of chronic lymphocytic leukemia. J Occup Med 1987;29: $136-41$.

7. Hernberg S, Kauppinen T, Riala R, Korkala ML, Asikainen U. Increased risk for primary liver cancer among women exposed to solvents. Scand $\mathbf{J}$ Work Environ Health 1988;14:356-65.

8. Kauppinen T, Riala R, Seitsamo J, Hernberg S. Primary liver cancer and occupational exposure. Scand J Work Environ Health 1992;18:18-25.

9. Copeland KT, Checkoway H, McMichael AJ, Holbrook $\mathrm{RH}$. Bias due to misclassification in the estimation of relative risk. Am J Epidemiol 1977;105:488-95.

10. Flegal KM, Brownie C, Haas JD. The effects of exposure misclassification on estimates of relative risk. Am J Epidemiol 1986;123:736-51.

11. Kleinbaum DG, Kupper LL, Morgenstern H. Epidemiologic research - principles and quantitative methods. New York, NY: Van Nostrand Reinhold Co, 1982: $220-41$.

12. Greenland S. The effect of misclassification in the presence of covariates. Am J Epidemiol 1980;112:564-9.

13. Miettinen OS. Estimability and estimation in casereferent studies. Am J Epidemiol 1976;103:226-35.

14. Cornfield $\mathbf{J}$. A statistical problem arising from retrospective studies. In: Proceedings of the 3rd Berkeley symposium; vol 4. Berkeley, CA: University of California Press, 1956:135-48.

15. Central Statistical Office of Finland. Statistical yearbook of Finland 1989. Helsinki: Central Statistical Office of Finland, 1989.

Received for publication: 7 May 1991 